\title{
Molecular mechanism of dominant expression in 3-methylcrotonyl-CoA carboxylase deficiency
}

\author{
M. R. BAumgartner \\ Division of Metabolism and Molecular Pediatrics, University Children's Hospital \\ Zürich, Switzerland \\ *Correspondence: Division of Metabolism and Molecular Pediatrics, University \\ Children's Hospital, Steinwiesstrasse 75, CH-8032 Zürich, Switzerland. \\ E-mail: Matthias.Baumgartner@kispi.unizh.ch
}

\begin{abstract}
Summary: Most enzyme deficiencies in humans are inherited as autosomal recessive traits. The term dominant negative is applied to mutant alleles in which a mutant protein interferes in one way or another with the function of the normal protein being produced from the wild-type allele in a heterozygote. Such a dominant negative effect usually involves homomeric or heteromeric proteins. 3-Methylcrotonyl-CoA carboxylase (MCC) is a heteromeric mitochondrial enzyme comprised of biotin containing MCC $\alpha$ subunits and smaller MCC $\beta$ subunits, encoded by the genes $M C C A$ and $M C C B$, respectively. Mutations in these genes cause isolated $\mathrm{MCC}$ deficiency, an autosomal recessive disorder with a variable phenotype ranging from severe neonatal to asymptomatic adult forms. Patients with MCC deficiency have a characteristic organic aciduria with greatly increased excretion of 3-hydroxyisovaleric acid (3-HIVA) and 3-methylcrotonylglycine (3-MCG). Here, two patients with elevated excretion of 3-MCG and 3-HIVA and partial deficiency of MCC are discussed, one of them with severe neurological symptoms. Both showed evidence of biotin responsiveness and were heterozygous for the missense mutation $M C C A$-R385S. Evidence is presented that $M C C A-\mathrm{R} 385 \mathrm{~S}$ is a dominant negative allele leading to biochemical abnormalities and clinical symptoms in heterozygous individuals and that it is responsive to pharmacological doses of biotin in vivo.
\end{abstract}

\section{SIGNIFICANCE OF DOMINANT AND RECESSIVE MUTANT ALLELES}

By definition, a phenotype expressed in the same way in both homozgotes and heterozygotes is dominant, whereas a phenotype expressed only in homozygotes or compound heterozygotes (or, for X-linked traits, hemizygotes) is recessive. In practice, this definition is too rigid to be useful. The distinction between dominant and recessive inheritance is not absolute and usually refers to the clinical phenotype 
associated with a particular allele. Accordingly, mutant alleles are classified as dominant or recessive on the basis of whether they can cause a change in phenotype when in the heterozygous or homozygous/compound heterozygous state, respectively.

The majority of enzyme deficiencies in humans are inherited as autosomal recessive traits. Although a recessive phenotype is defined as being clinically undetectable in heterozygotes, heterozygotes for many of these conditions exhibit subtle differences in phenotype when examined at the cellular or biochemical level, and these differences may be enhanced by environmental factors. Even when clinically 'normal', individuals who are heterozygous for recessive loss of function alleles often have demonstrable metabolic differences and always have demonstrable differences at the protein level. Such subtle phenotypic effects may be more common than is generally recognized and may contribute to phenotypes usually considered to be complex traits. For example, heterozygosity for cystathionine $\beta$-synthase-deficient homocystinuria is probably a risk factor for vascular disease (Clarke 2002), dementia and Alzheimer disease (Loscalzo 2002), and osteoporotic fractures in the elderly (Raisz 2004).

Whether a mutant allele generates a dominant or a recessive disorder is determined by two factors: (1) the effect of the mutant allele on the function of the gene product, and (2) the tolerance of the biological system (e.g. the blood glucose homeostatic system) to perturbation of that particular gene product (Kacser and Burns 1981). Tolerant systems tend to result in recessive phenotypes, less-tolerant systems tend to result in dominant phenotypes. Examples where a heterozygous loss-of-function allele, i.e. haploinsufficiency, causes a disease phenotype include several forms of porphyria (Anderson et al 2001), familial hypercholesterolaemia (Goldstein et al 2001), and type I osteogenesis imperfecta (Byers and Cole 2002). However, for most metabolic pathways, quantitative analysis demonstrates that a large change in enzyme activity results in a negligible change in flux, which explains why most enzyme deficiencies are recessive (Kacser and Burns 1981).

\section{DOMINANT NEGATIVE EFFECT}

Instead of simple deficiency or dysfunction of the protein product of a mutant allele, an abnormal protein may be synthesized that causes an abnormal phenotype by interfering with the protein product of the normal allele in heterozygous individuals. Such an effect of the protein product of a mutant allele on the function of the protein product of the wild-type allele is termed dominant negative. A dominant negative effect of the protein product of a mutant allele usually involves homomeric or heteromeric proteins. Typically, the protein product of a dominant negative allele is functionally inactive and in addition has the property of inhibiting the activity of the protein product of the normal allele, thus causing the cell to be deficient in the function of the normal protein product (Herskowitz 1987). To achieve this, the dominant negative mutant protein product must be stable and able to assemble into the normal multimeric protein complex. This will lead to the formation of nonfunctional multimers. Such a mutant allele has a dominant effect because its phenotype is manifested despite the presence of the wild-type allele. 


\section{SUBUNIT STRUCTURE AND GENE DOSAGE EFFECTS}

Evidence for a deviant gene dosage effect at the polypeptide level in cystathionine $\beta$-synthase deficiency (classical homocystinuria) was first reported by Uhlendorf and colleagues (Uhlendorf et al 1973), reviewed by Mudd and Levy (1978) and later by McGill and colleagues (McGill et al 1990). They pointed out that the enzymatic activity in heterozygotes is almost invariably is less than $50 \%$ of the mean normal activity, or on average one-third normal, instead of half-normal (McGill et al 1990).

If a human enzyme possesses at least two copies of any subunit (i.e. if it contains $\alpha_{2}$ ), a tentative explanation for a deviant gene dosage effect, such as the one in classical homocystinuria, is provided in Figure 1. Let us suppose that there are two copies of the same subunit, an active, wild-type subunit, $\alpha$ and a mutant inactive subunit, $\alpha^{\prime}$. Heterozygous individuals who synthesize normal and mutant polypeptide chains, when the mutant allele is stable, are likely to assemble three types of enzyme molecules: $\alpha \alpha$ (wild-type homomeric), $\alpha^{\prime} \alpha^{\prime}$ (mutant homomeric) and $\alpha \alpha^{\prime} / \alpha^{\prime} \alpha$ (heterodimeric hybrid-molecule form) (Figure 1). If it is assumed that $\alpha$ and $\alpha^{\prime}$ are present in equal numbers and that assembly is random, molecules containing $\alpha \alpha, \alpha \alpha^{\prime} / \alpha^{\prime} \alpha$ and $\alpha^{\prime} \alpha^{\prime}$ will represent $25 \%, 50 \%$ and $25 \%$ of the total enzyme molecules, respectively. The specific activity of the native enzyme containing two wild-type alleles may be taken as $100 \%$; likely the activity of the mutant enzyme containing 2 mutant alleles will be $0 \%$. Thus, the total activity in the heterozygote will depend upon the activity of the hybrid molecule. If there is no interaction between the associated normal and mutant polypeptide chains, the heterozygote will have a total activity of $50 \%$ of normal. However, if there is a (dominant) negative interaction, so that the hybrid molecule form contributes only a diminished catalytic activity, the heterozygote will have less than $50 \%$ of the normal total activity. In the extreme, the hybrid molecule will have no activity and thus the

\begin{tabular}{|c|c|c|c|c|c|}
\hline $\begin{array}{l}\text { Heterozygous } \\
\text { Individual }\end{array}$ & $\alpha \alpha$ & $\begin{array}{l}\infty \\
\alpha^{\prime} \alpha\end{array}$ & $\infty_{\alpha \alpha^{\prime}}$ & $\oint_{\alpha^{6} \alpha^{6}}$ & $\begin{array}{c}\text { Total } \\
\text { enzyme } \\
\text { activity }\end{array}$ \\
\hline & $100 \%$ & $?$ & $?$ & $0 \%$ & $?$ \\
\hline No interaction & $100 \%$ & $50 \%$ & $50 \%$ & $0 \%$ & $50 \%$ \\
\hline Negative interaction & $100 \%$ & $0 \%$ & $0 \%$ & $0 \%$ & $25 \%$ \\
\hline
\end{tabular}

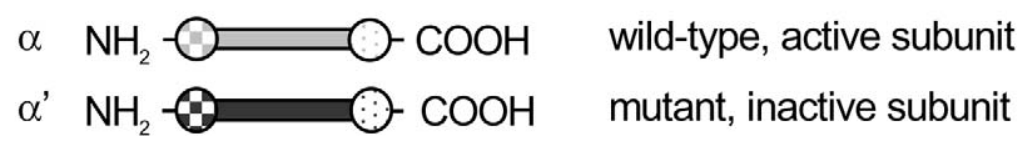

Figure 1 Subunit structure and gene dosage effects in a heterozygous individual 
heterozygote total activity would be only $25 \%$ (Figure 1). Such an exaggerated gene dosage effect (negative allelic complementation) is assumed to be the cause of less than half-normal enzymatic activity in heterozygotes for cystathionine $\beta$-synthasedeficient homocystinuria (McGill et al 1990).

\section{3-METHYLCROTONYL-COA CARBOXYLASE (MCC) DEFICIENCY}

3-Methylcrotonyl-CoA carboxylase (MCC, EC 6.4.1.4) is a biotin-dependent enzyme that catalyses the fourth step in the catabolism of leucine. It carboxylates 3-methylcrotonyl-CoA to 3-methylglutaconyl-CoA in an ATP-requiring reaction using bicarbonate as the source of the carboxyl group (Sweetman and Williams 2001). MCC is a heteromeric mitochondrial enzyme comprised of biotin-containing MCC $\alpha$ subunits and smaller MCC $\beta$ subunits, encoded by $M C C A$ and $M C C B$, respectively. Mutations in these genes cause MCC deficiency (also known as methylcrotonylglycinuria (Mckusick 210200/210210)), an autosomal recessive disorder with a variable phenotype ranging from severe neonatal onset to asymptomatic forms in adults (Baumgartner et al 2001; Gallardo et al 2001). Some patients present in the neonatal period with seizures and hypotonia (Bannwart et al 1992; Lehnert et al 1996); others are asymptomatic women discovered only by detection of abnormal metabolites in the neonatal screening samples of their healthy babies (Gibson et al 1998). Most patients, however, are asymptomatic until an episode of acute metabolic decompensation following intercurrent illness in early childhood leads to their diagnosis. Patients with MCC deficiency have a characteristic organic aciduria with greatly increased excretion of 3-hydroxyisovaleric acid (3-HIVA) and 3-methylcrotonylglycine (3-MCG), usually in combination with a severe secondary carnitine deficiency. In addition, 3-hydroxyisovalerylcarnitine is found in blood and urine (Sweetman and Williams 2001).

MCC deficiency can be confirmed by demonstrating deficient MCC activity in the presence of normal activity of another biotin-dependent carboxylase in cultured skin fibroblasts or isolated lymphocytes. MCC activity in cultured fibroblasts of patients is usually less than $2 \%$ of the mean control value. Two patients with higher residual activity in cultured fibroblasts varying from $4 \%$ to $12 \%$ have been reported (Tuchman et al 1993; Wiesmann et al 1998). No correlation between the level of residual enzyme activity measured in vitro and clinical presentation has been observed. Here, two patients with a biochemical and, in one case, a clinical phenotype of MCC deficiency, both responsive to biotin, are discussed (Baumgartner et al 2004).

\section{BIOTIN-RESPONSIVE MCC DEFICIENCY IN TWO HETEROZYGOTES FOR $M C C A$-R385S}

The first patient presented at 3 months with seizures and progressive psychomotor retardation. Metabolic investigation at 2 years revealed elevated excretion of 3-MCG and 3-HIVA, suggesting MCC deficiency. High-dose biotin therapy was associated with correction of the organic aciduria within 4 weeks, a dramatic reduction in seizures and normalization of the EEG. The second patient, a newborn detected by tandem mass spectrometry newborn screening, displayed the same biochemical 
phenotype and remained asymptomatic with biotin up to the present age of 18 months (Baumgartner et al 2004).

Enzymatic determination of MCC activity in cultured fibroblasts revealed a partial, but specific, MCC deficiency (Baumgartner et al 2004). In both, residual fibroblast MCC activity was not abnormally sensitive to biotin depletion nor was it enhanced by addition of high concentrations of biotin to the medium. These results rule out holocarboxylase synthase (HCS) deficiency as the cause of reduced MCC activity but do not explain the clinical features or the persistent organic aciduria in our patients.

Mutation analysis of the $M C C A$ and $M C C B$ genes revealed that both patients are heterozygous for a previously described missense mutation, $M C C A-\mathrm{R} 385 \mathrm{~S}$, and a known polymorphism, $M C C A$-P464H (Obata et al 2001). Despite an extensive search for a functional mutation on the second allele by RT-PCR of mRNA of the entire $M C C A$ and $M C C B$ ORF as well as by amplification and sequencing of all $M C C A$ exons and flanking intronic splice sites from genomic DNA, no other coding alterations were identified (Baumgartner et al 2004). In earlier studies, $M C C A$-R385S conferred no MCC activity when transfected into reference $\mathrm{MCC} \alpha$-deficient cells (Baumgartner et al 2001). The $M C C A$-R385S allele was identified in one of 132 caucasian control chromosomes (Baumgartner et al 2001). Interestingly, $M C C A-\mathrm{R} 385 \mathrm{~S}$ appears to be the most frequent allele found in MCC-deficient patients of German origin. Among seven such patients, one is homozygous and six are compound heterozygous for $M C C A-\mathrm{R} 385 \mathrm{~S}$ (M.R. Baumgartner and M.F. Dantas unpublished results).

\section{MCCA-R385S EXHIBITS AN ALLELE-SPECIFIC DOMINANT NEGATIVE EFFECT}

The missense allele $M C C A-\mathrm{R} 385 \mathrm{~S}$ is unusual in that it is the only one of seven detected in six MCC $\alpha$-deficient patients for which protein blot analysis of fibroblast homogenates shows the presence of MCC $\alpha$ protein $(\mathrm{CRM}+)$ (Baumgartner et al 2001; Gallardo et al 2001).

An arginine at position 385 (or the corresponding position) is strictly conserved in mammalian, plant, fungal and bacterial carboxylases (Jitrapakdee and Wallace 1999; Samols et al 1988), and the corresponding residue in the biotin carboxylase domain of E. coli acetyl-CoA carboxylase (R338) has been shown to be part of a positively charged pocket for bicarbonate binding (Thoden et al 2000).

To explain the biochemical abnormalities (and clinical phenotype in patient 1) seen in vivo in these patients, a dominant negative influence of the mutant R385S MCC $\alpha$ subunit on the activity of $M C C A$-wild type was hypothesized. To test this, both alleles were cotransfected into an SV40T-transformed MCC $\alpha$-deficient reference cell line and $\mathrm{MCC}$ activity was measured $72 \mathrm{~h}$ later. In two separate experiments, cotransfection of $M C C A$-wild type allele with vector without insert restored $\mathrm{MCC}$ activity to $55 \%$ of untransfected control fibroblasts while cotransfection of $M C C A$-wild type with $M C C A-\mathrm{R} 385 \mathrm{~S}$ restored MCC activity only to $25 \%$, i.e. to about $50 \%$ of that obtained with wild type coexpressed with vector without insert (Figure 2) (Baumgartner et al 2004). In contrast, co-transfection of $M C C A$-wild type with either $M C C A$-A289V 
or MCCA-L437P restored MCC activity to the same level as that obtained with wild type coexpressed with vector without insert (Figure 2). Thus, the reduction of MCC activity is specific for $M C C A$-R385S. The same experiment using the $M C C A$-wild type construct with histidine instead of a proline at codon 464 (MCCA-P464H) gave similar results (Baumgartner et al 2004). Thus, the dominant negative effect of $M C C A-\mathrm{R} 385 \mathrm{~S}$ when coexpressed with the wild-type allele is independent of the $\mathrm{P} 464 \mathrm{H}$ polymorphism.

MCC $\alpha$ R385S fulfills all of the above-mentioned criteria of a dominant negative allele: in contrast to the protein products of other MCCA missense alleles, the MCC $\alpha$ $\mathrm{R} 385 \mathrm{~S}$ protein is stable (Baumgartner et al 2001; Gallardo et al 2001). On protein blot analysis using avidin alkaline phosphatase as a probe, MCC $\alpha$ R385S accumulates to levels equal to or even greater than normal (Baumgartner et al 2001). Despite this, expression studies clearly show that the MCC $\alpha$ R $385 \mathrm{~S}$ is catalytically inactive (Baumgartner et al 2001; Desviat et al 2003). Moreover, the results of cotransfection experiments show that expression of MCC $\alpha$ R385S but not two other MCCA missense alleles inhibits the function of coexpressed wild-type MCC $\alpha$ protein (Baumgartner et al 2004). Taken together, these data strongly support the hypothesis of a dominant negative effect of MCC $\alpha$ R385S on the wild-type protein and thus on MCC activity.

Additional evidence comes from the recent studies of Sloane and Waldrop, who used the purified homodimer of the biotin carboxylation subunit of E. coli acetyl-CoA carboxylase to study the kinetic properties of mutant proteins (Sloane and Waldrop 2004). They showed that E. coli biotin carboxylase-R338S, the missense mutant corresponding to $M C C A-\mathrm{R} 385 \mathrm{~S}$, exhibited a dominant negative effect on the function

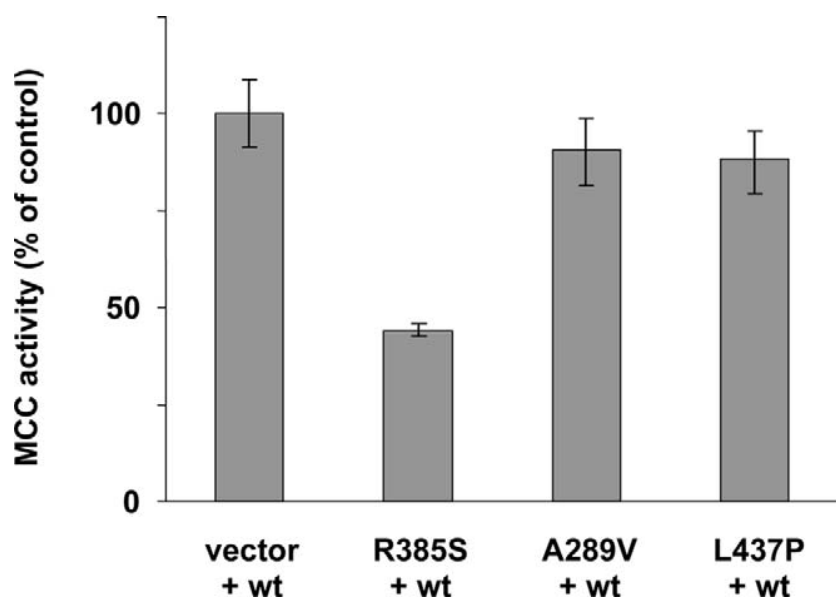

Figure 2 The effect of coexpression of $M C C A$ missense alleles and wild-type $M C C A$. MCC-deficient cells were cotransfected with wild-type $M C C A$ plus $M C C A$ alleles with the indicated missense mutation. Activities represent mean and range of duplicates. MCC activity of cells cotransfected with wild-type MCCA and vector without insert was set at $100 \%$. Modified from Baumgartner et al (2004) 
of the wild-type active site by negative cooperativity with respect to bicarbonate concentration (Sloane and Waldrop 2004). Furthermore, they presented evidence that the degree of negative cooperativity is decreased upon increasing concentrations of biotin. These data support the hypothesis of a dominant negative effect of MCC $\alpha$ R385S on the wild-type protein and thus on MCC activity.

\section{WHY ARE OTHER MCCA-R385S HETEROZYGOTES ASYMPTOMATIC?}

The $M C C A$-R385S heterozygotes with normal urinary organic acids studied in our laboratory were all adults. Thus, one possible explanation is that the metabolic flux through the pathway is less in adults than in infants and children. This would be consistent with the identification of asymptomatic adults with severe MCC deficiency (Baumgartner et al 2001; Gibson et al 1998). Additional factors that could influence the phenotypic consequences of MCC deficiency include the extent to which the pathway is stressed by dietary or other factors (e.g. excessive protein breakdown associated with an intercurrent infection).

Alternatively, the amount of functional MCC $\alpha$ produced from the wild-type allele may vary. Recent studies have suggested that alleles of as many as half of all genes examined exhibit a 2-4-fold or more allelic variation in expression and that this characteristic segregates with the alleles from one generation to the next (Lo et al 2003; Yan et al 2002). If this is the case for MCCA, then the expression level of the wild-type allele would be an additional variable affecting the consequences of heterozygosity for a nonfunctional allele. A heterozygote with a low-expressing wild-type allele might be clinically and/or biochemically symptomatic. Conversely, a heterozygote with a high-expressing wild-type allele would be normal. However, allelic expression studies showed about equal expression of both alleles in the two patients (Baumgartner et al 2004).

Finally, normal variation in genes whose protein products have the potential to modify the function of MCC or the flux through the pathway could also influence the phenotype of MCC deficiency. $M C C B$ and $H C S$ are obvious candidate modifier genes for $M C C A$, but no sequence variation in either of these was found in our patients (Baumgartner et al 2004).

Surprisingly, the clinical symptoms in patient 1 and the biochemical phenotype in both patients appeared to respond to high doses of biotin. A biotin-responsive form of MCC deficiency has not previously been reported (Sweetman and Williams 2001). Biotin responsiveness, however, is consistent with the observation that $M C C A-\mathrm{R} 385 \mathrm{~S}$ produces a stable protein and that other cofactor-responsive disorders are allele specific (e.g. holocarboxylase synthetase deficiency) (Dupuis et al 1999). It also is in accordance with the findings of Sloane and Waldrop, who showed that biotin decreases the negative cooperativity of $E$. coli biotin carboxylase with a missense mutation in the residue corresponding to $M C C A$-R385S (Sloane and Waldrop 2004). To provide further evidence for biotin responsiveness, additional clinical, biochemical and molecular studies on and off biotin are needed.Therefore, careful documentation of the consequences of biotin administration in newly diagnosed patients is recommended. 


\section{REFERENCES}

Anderson KE, Sassa S, Bishop DF, Desnick RJ (2001) Disorders of heme biosynthesis: X-linked sideroblastic anemia and the porphyrias. In: Scriver CR, Beaudet AL, Sly WS, Valle D, eds. Childs B, Kinzler KW, Vogelstein B assoc. eds. The Metabolic and Molecular Bases of Inherited Disease, 8th edn. New York: McGraw-Hill, 2991-3062.

Bannwart C, Wermuth B, Baumgartner R, Suormala T, Weismann UN (1992) Isolated biotin-resistant deficiency of 3-methylcrotonyl-CoA carboxylase presenting as a clinically severe form in a newborn with fatal outcome. J Inherit Metab Dis 15: 863-868.

Baumgartner MR, Almashanu S, Suormala T, et al (2001) The molecular basis of human 3-methylcrotonyl-CoA carboxylase deficiency. J Clin Invest 107: 495-504.

Baumgartner MR, Dantas MF, Suormala T, et al (2004) Isolated 3-methylcrotonyl-CoA carboxylase deficiency: evidence for an allele-specific dominant negative effect and responsiveness to biotin therapy. Am J Hum Genet 75: 790-800.

Byers PH, Cole W (2002) Osteogenesis imperfecta. In: Royce PM, Steinmann B, eds. Connective Tissue and Its Heritable Disorders. New York: Wiley-Liss. 385-430.

Clarke R (2002) An updated review of the published studies on homocysteine and cardiovascular disease. Int $J$ Epidemiol 31: 70-71.

Desviat LR, Pérez-Cerdá C, Pérez B, et al (2003) Functional analysis of MCCA and MCCB mutations causing methylcrotonylglycinuria. Mol Genet Metab 80: 315-320.

Dupuis L, Campeau E, Leclerc D, Gravel RA (1999) Mechanisms of biotin responsiveness in biotin-repsonsive multiple carboxylase deficiency. Mol Genet Metab 66: 80-90.

Gallardo ME, Desviat LR, Rodrígues JM, et al (2001) The molecular basis of 3-methylcrotonylglycinuria, a disorder of leucine catabolsim. Am J Hum Genet 68: 334-346.

Gibson KM, Bennett MJ, Naylor EW, Morton DH (1998) 3-Methylcrotonyl-coenzyme A carboxylase deficiency in Amish/Mennonite adults identified by detection of increased acylcarnitines in blood spots of their children. J Pediatr 132: 519-523.

Goldstein JL, Hobbs HH, Brown MS (2001) Familial hypercholesterolemia. In: Scriver CR, Beaudet AL, Sly WS, Valle D, eds. Childs B, Kinzler KW, Vogelstein B, assoc. eds. The Metabolic and Molecular Bases of Inherited Disease, 8th edn. New York: McGraw-Hill, 2863-2913.

Herskowitz I (1987) Functional inactivation of genes by dominant negative mutations. Nature 329: $219-222$

Jitrapakdee S, Wallace JC (1999) Structure, function and regulation of pyruvate carboxylase. Biochem J 340: 1-16.

Kacser H, Burns JA (1981) The molecular basis of dominance. Genetics 97: 639.

Lehnert W, Niederhoff H, Suormala T, Baumgartner ER (1996) Isolated biotin-resistant 3-methylcrotonyl-CoA carboxylase deficiency: long-term outcome in a case with neonatal onset. Eur J Pediatr 155: 568-572.

Lo $\mathrm{H}$, Wang $\mathrm{Z}$, $\mathrm{Hu} \mathrm{Y}$, et al (2003) Allelic variation in gene expression is common in the human genome. Genome Res 13: 1855-1862.

Loscalzo J (2002) Homocysteine and dementias. N Engl J Med 346: 466-468.

McGill JJ, Mettler G, Rosenblatt DS, Scriver CR (1990) Detection of heterozygotes for recessive alleles. Homocysteinemia: paradigm of pitfalls in phenotypes. Am J Med Genet 36: $45-52$.

Mudd SH, Levy HL (1978) Disorders of transsulfuration. In: Stanbury JB, Wyngaarden JB, Fredrickson DS, eds. The Metabolic Basis of Inherited Disease. New York: McGraw-Hill, 458-503.

Obata K, Fukuda T, Morishita R, et al (2001) Human biotin-containing subunit of 3-methylcrotonyl-CoA carboxylase gene (MCCA): cDNA sequence, genomic organization, localization to chromosomal band 3q27, and expression. Genomics 72: 145-152.

Raisz LG (2004) Homocysteine and osteoporotic fractures - culprit or bystander? N Engl J Med 350: 2089-2090. 
Samols D, Thornton CG, Murtif VL, Kumar GK, Haase FC, Wood HG (1988) Evolutionary conservation among biotin enzymes. J Biol Chem 263: 6461-6464.

Sloane V, Waldrop GL (2004) Kinetic characterization of mutations found in propionic acidemia and methylcrotonylglycinuria. Evidence for cooperativity in biotin carboxylase. $J$ Biol Chem 279: 15772-15778.

Sweetman L, Williams JC (2001) Branched chain organic acidurias. In: Scriver CR, Beaudet AL, Sly WS, Valle D, eds; Childs B, Kinzler KW, Vogelstein B, assoc. eds. The Metabolic and Molecular Bases of Inherited Disease, 8th edn. New York: McGraw-Hill, 2125-2163.

Thoden JB, Blanchard CZ, Holden HM, Waldrop GL (2000) Movement of biotin carboxylase B-domain as a result of ATP binding. J Biol Chem 275: 16183-16190.

Tuchman M, Berry SA, Thuy LP, Nyhan WL (1993) Partial methylcrotonyl-coenzyme A carboxylase deficiency in an infant with failure to thrive, gastrointestinal dysfunction and hypertonia. Pediatrics 91: 664-666.

Uhlendorf BW, Conerly EB, Mudd SH (1973) Homocystinuria: studies in tissue culture. Pediatr Res 7: 645-658.

Wiesmann UN, Suormala T, Pfenninger J, Baumgartner ER (1998) Partial 3-methylcrotonyl-CoA carboxylase deficiency in an infant with fatal outcome due to progressive respiratory failure. Eur J Pediatr 157: 225-229.

Yan H, Yuan W, Vleculescu V, Vogelstein B, Kinzler KW (2002) Allelic variation in human gene expression. Science 297: 1143. 